\title{
Mammographic Density and Prediction of Nodal Status in Breast Cancer Patients
}

\author{
Einfluss der mammografischen Dichte auf die Prädiktion \\ des Nodalstatus bei Mammakarzinompatientinnen
}

Authors

Affiliations

C. C. Hack ${ }^{1}$, L. Häberle ${ }^{1}$, K. Geisler ${ }^{1}$, R. Schulz-Wendtland ${ }^{2}$, A. Hartmann ${ }^{3}$, P. A. Fasching ${ }^{1}$, M. Uder ${ }^{2}$, D. L. Wachter ${ }^{3}$, S. M. Jud ${ }^{1}$, C. R. Loehberg ${ }^{1}$, M. P. Lux ${ }^{1}$, C. Rauh ${ }^{1}$, M. W. Beckmann ${ }^{1}$, K. Heusinger ${ }^{1}$

\footnotetext{
${ }^{1}$ Department of Gynecology and Obstetrics, University Hospital Erlangen, Friedrich-Alexander University Erlangen-Nuremberg, Erlangen

2 Institut für gynäkologische Radiologie, Universitätsklinikum Erlangen, Erlangen

3 Institute of Pathology, University Hospital Erlangen, Erlangen
}

\author{
Key words \\ - nodal status \\ - estrogen receptor \\ progesterone receptor \\ - Ki-67 \\ - breast cancer \\ - mammographic density \\ Schlüsselwörter \\ - Nodalstatus \\ - Östrogenrezeptor \\ - Progesteronrezeptor \\ - Ki-67 \\ - Mammakarzinom \\ - mammografische Dichte
}

\section{received 12.2.2013 \\ revised 14.2.2013 \\ accepted 15.2.2013}

Bibliography

DOI http://dx.doi.org/

10.1055/s-0032-1328291

Geburtsh Frauenheilk 2013; 73 :

136-141 @ Georg Thieme

Verlag KG Stuttgart · New York . ISSN 0016-5751

\section{Correspondence}

Prof. Peter A. Fasching, MD

University Hospital Erlangen

Department of Gynecology and Obstetrics

Universitätsstraße 21-23

91054 Erlangen

peter.fasching@uk-erlangen.de

\section{Abstract \\ V}

Aim: Nodal status remains one of the most important prognostic factors in breast cancer. The cellular and molecular reasons for the spread of tumor cells to the lymph nodes are not well understood and there are only few predictors in addition to tumor size and multifocality that give an insight into additional mechanisms of lymphatic spread. Aim of our study was therefore to investigate whether breast characteristics such as mammographic density (MD) add to the predictive value of the presence of lymph node metastases in patients with primary breast cancer.

Methods: In this retrospective study we analyzed primary, metastasis-free breast cancer patients from one breast center for whom data on MD and staging information were available. A total of 1831 patients were included into this study. MD was assessed as percentage MD (PMD) using a semiautomated method and two readers for every patient. Multiple logistic regression analyses with nodal status as outcome were used to investigate the predictive value of PMD in addition to age, tumor size, Ki-67, estrogen receptor (ER), progesterone receptor (PR), grading, histology, and multi-focality.

Results: Multifocality, tumor size, Ki-67 and grading were relevant predictors for nodal status. Adding PMD to a prediction model which included these factors did not significantly improve the prediction of nodal status ( $p=0.24$, likelihood ratio test).

Conclusion: Nodal status could be predicted quite well with the factors multifocality, tumor size, Ki67 and grading. PMD does not seem to play a role in the lymphatic spread of tumor cells. It could be concluded that the amount of extracellular matrix and stromal cell content of the breast which is reflected by MD does not influence the probability of malignant breast cells spreading from the primary tumor to the lymph nodes.

\section{Zusammenfassung \\ $\nabla$}

Ziel: Der Nodalstatus ist nach wie vor einer der wichtigsten Prognosefaktoren für Patientinnen mit Mammakarzinom. Die zellulären und molekularen Gründe hierfür sind nicht gut verstanden, und es gibt nur wenige Prädiktoren außer Tumorgröße und Multifokalität, die einen zusätzlichen Einblick in die Mechanismen der lymphatischen Metastasierung geben. Ziel unserer Studie war es daher zu untersuchen, ob die mammografische Dichte (MD) als Korrelat der Stroma- und Extrazellularmatrixmenge mit dem Auftreten von Lymphknotenmetastasen korreliert.

Methoden: In dieser retrospektiven Studie sind Patientinnen mit pimärem, metastasenfreien Mammakarzinom eingeschlossen wurden, die in einer Institution behandelt wurden. Von allen Patientinnen musste die MD bekannt sein, genauso wie die Staging-Informationen. Die MD wurde semiautomatisiert als prozentuale MD (PMD) von 2 unabhängigen Gutachtern beurteilt. Logistische Regressionsanalysen mit dem Nodalstatus als Zielvariable wurden durchgeführt, um den zusätzlichen prädiktiven Wert von PMD zusätzlich zu Alter, Tumorgröße, Ki-67, Östrogenrezeptorstatus (ER) und Progesteronrezeptorstatus (PR), Grading, Tumortyp und Multifokalität zu bestimmen.

Ergebnisse: Multifokalität, Tumorgröße, Ki-67 und Grading waren relevante Prädiktoren des Nodalstatus. Die Hinzunahme von PMD zu diesen Faktoren konnte die Vorhersage des Nodalstatus nicht signifikant verbessern ( $p=0,24$, LikelihoodRatio-Test).

Schlussfolgerung: Der Nodalstatus konnte relativ gut durch die Parameter Multifokalität, Tumorgröße, Ki-67 und Grading vorhergesagt werden. PMD scheint keine Rolle zu spielen bei der Lymphknotenmetastasierung aus dem Primärtumor. Somit scheint die Menge an Extrazellularmatrix und Stroma, welche das Korrelat der MD 
ist, keinen Einfluss auf die Wahrscheinlichkeit zu haben, mit der Brustkrebszellen lymphatisch metastasieren.

\section{Introduction}

Mammographic breast density (MD) is one of the most important risk factors for breast cancer (BC) [1]. Women with a high MD have a to fivefold increased risk for breast cancer [2-4]. It has been shown that women who develop a high MD after postmenopausal hormone therapy have an increased risk for breast cancer and healthy women who develop a low MD after the intake of tamoxifen have a decreased breast cancer risk [5,6]. Thus, MD is not only a risk indicator but can even serve as a therapy response marker with regard to breast cancer risk.

There is limited data on MD and prognosis after the diagnosis of an invasive breast cancer. A large cohort study based in the United States did not find a clear association between mammographic density and prognosis [7]. Only in some subgroups such as women with a high body mass index and women with large tumors, did low MD seem to be associated with a worse prognosis [7]. An analysis of the baseline mammogram in the Swedish mammography screening program yielded a higher risk for breast cancer death in women with a higher MD [8] and a smaller study found a high MD to be an independent predictor of locoregional recurrence after breast-conserving surgery and radiotherapy for invasive breast cancer [9]. Taken together, these results are rather inconsistent and warrant further examination of the correlation of MD with prognosis or other prognostic factors. Additionally, MD has been associated with specific tumor characteristics that are linked to prognosis as well. One study showed an association between progesterone receptor (PR) positivity and MD and between estrogen receptor (ER) beta and MD [10]. Furthermore it has been reported that MD can increase the risk for ER+ PR+ tumors but not for ER- PR- tumors [11]. In a case control study MD was associated with the risk for both ER+ PR+ HER2+ and triple negative breast cancer [12]. The largest case control study so far showed that MD increased the risk for high grade tumors and ER negative tumors [13]. We previously could show that a high MD was correlated with ER negativity and PR positivity [14]. Other studies showed different results [15]. Some association has also been reported on the proliferation marker Ki-67. It seems that in some subgroups (low BMI, HRT users and low PR expression) MD was correlated with proliferation in the tumors [16].

Recently it has been shown that a high MD has a histological correlate of high extracellular matrix similar to breast cancer tumors [17]. It could be therefore hypothesized that this might have an influence on tumor spread and lymphogenic metastases in the breast. In fact, a small study showed an association between low MD and lymph node status [18]. Therefore the aim of this study was to examine this correlation in a large case-only study with high quality MD measures, specifically whether MD can improve the prediction of lymph node status in addition to other, previously reported biomarkers that are correlated to a positive lymph node status.

\section{Patients and Methods}

$\nabla$

\section{Patient selection}

The patients were selected from the breast cancer database at the University Breast Center for Franconia. A total of 5,110 patients with invasive $B C$ are documented in the database for the period 1995-2008. In the analysis presented here, patients were excluded in the following hierarchical order: no mammogram performed at the University Breast Center at the time of primary diagnosis or bilateral synchronous breast cancer (excluding 1,989 patients, 485 of whom had bilateral cancer); primary distant metastases at primary diagnosis (excluding 502 patients) unknown nodal status (excluding 788 patients). The final study population consisted of 1,831 patients with incident, unilateral, invasive BC and available MD. The study was approved by the Ethics Committee of the Medical Faculty of Friedrich-Alexander University Erlangen-Nuremberg.

\section{Clinical Data}

All patient characteristics and tumor characteristics were documented as part of the certification processes required by the German Cancer Society (Deutsche Krebsgesellschaft) and by the German Society for Breast Diseases (Deutsche Gesellschaft für Senologie) [19] as described before [20-23]. Certification requires tumor characteristics, treatment data, some epidemiological data, histopathological characteristics, tumor treatments, and followup to be documented and audited annually.

\section{Histopathology}

In the course of routine patient care, dedicated breast pathologists at the University Breast Center for Franconia examined pathologic specimens from all of the patients included in this study. The histological type, grade, resection status, and TNM stage were determined, and expression of ER, PR, and HER2 was analyzed by immunohistochemistry in accordance with standard practice. ER and PR status are based on estimates of the percentage of clearly positively stained nuclei of cancer cells (from 0 to 100\%). Ki-67 staining was performed with the MIB1 clone, yielding the percentage of positive nuclei of tumor cells (from 0 to 100\%). HER2 testing was performed with the DAKO test (Dako, Denmark). Information about tumor characteristics was subsequently transferred from the histopathological reports our clinical database.

\section{Mammographic Density Measures}

The quantitative computer-based threshold density assessments and breast area measurements were made by two different readers with extensive training in the method used. Each mammogram was read by both readers independently of each other. The assessment method has been described and validated previously elsewhere [24]. Briefly, the images (analog images and printouts of processed digital images) were digitized using the CAD PRO Advantage film digitizer (VIDAR, Herndon, Virginia, USA), and for assessment of the density fraction, the reader used the Madena software program, Version X (Eye Physics, LLC, Los Alamitos, California, USA) [24]. All mammograms were read in random order by two different observers who were unaware of any previous classifications or pathological findings. The average of the 
two observers' values for percentage mammographic density (PMD) was used for this analysis, into which only measurements of contralateral cranio-caudal (CC) images were included [36,37].

\section{Statistical Considerations}

Patients were grouped according to their nodal status (negative versus positive). Their characteristics were compared using appropriate unpaired statistical tests. Student's t-tests were used for normally distributed characteristics, Wilcoxon rank-sum tests for ordinal-categorical or continuous non-normally distributed characteristics, and $\mathrm{X}^{2}$ tests for categorical characteristics.

Multiple logistic regression analyses with nodal status as outcome were used to investigate the predictive value of PMD in addition to the well-known predictive factors of age at diagnosis (continuous), tumor size (continuous), Ki-67 (continuous), ER (positive vs. negative), PR (positive vs. negative), grading (ordinal), histology (lobular, ductal, others), and multi-focality (yes vs. no).

Initially, for each continuous predictor, several natural cubic spline logistic regression models, which differ from each other by their degrees of freedom (from 1 to 4 ), were fitted to explore how the odds ratios (ORs) changed with increasing predictor value [25]. For instance, a cubic spline model with one degree of freedom corresponds to a linear usage of the predictor. The Akaike information criterion (AIC) was applied to choose the best model in order to obtain the suitable degree of freedom for the specific continuous predictor in the following analyses. The AIC was used because it measures goodness of fit and also takes overfitting into account by penalizing complex models.

The main analysis started with a bootstrap-based selection procedure to identify a set of standard characteristics that were associated with nodal status. Five hundred bootstrap samples of the same size as the data set were selected with replacements. For each bootstrap sample, a backward stepwise variable selection procedure, starting with a logistic regression model with the well-known predictors mentioned above but without PMD, was carried out to obtain the best model in accordance with the AIC. The retained predictors from each bootstrap sample were recorded, and a final variable selection was made by applying a procedure proposed by Sauerbrei and Schumacher [26]. In this procedure the most frequently selected $(>70 \%)$ predictors were chosen, and, to address correlation among predictors, the predictor with the larger frequency out of each highly frequent predictor pair (>90\%) was chosen. A logistic regression model with these finally selected predictors was fitted to the original data set (the final model without PMD). Repetitive variable selections were carried out to get a stable stepwise regression result [27].

Next, the bootstrap-based variable selection procedure from above was carried out again, with PMD, the predictors of the final model without PMD, and the interactions between these predictors and PMD, but with the condition that the predictors of the final model without PMD were kept during the stepwise variable selections. Again, a logistic regression model with the finally selected predictors was fitted to the original data set (the final model with PMD).

The final model with PMD was compared with the final model without PMD using the likelihood ratio test. A significant test result means that PMD has a predictive value independent of the well-known predictors considered. The interaction terms of the final model with PMD demonstrate differences within subgroups with regard to the predictive effect of PMD. ORs with 95\% confidence intervals based on the final model with PMD were shown.
The predictive ability of the final model with PMD in terms of discrimination and calibration was measured with the area under the receiver operator curve (AUC) and the Hosmer-Lemeshow statistic. The AUC ranges from 0.5 (no discrimination of nodalpositive and nodal-negative patients) to 1 (perfect discrimination). Following Hosmer and Lemeshow, patients were ordered with respect to the predicted probability of positive lymph node status and grouped into equal-sized categories based on percentiles. Frequencies of predicted events were compared with frequencies of observed events using a scatter plot and with the Hosmer-Lemeshow $\mathrm{X}^{2}$ test. A large $\mathrm{p}$-value indicates a satisfactory calibration.

Model building was evaluated by 10 -fold cross-validation with 20 repetitions. For this purpose the model-building process was done for each training set, resulting in final models with PMD. These models were fitted to the training sets, and AUCs were calculated with patients of the validation sets. The average AUC was taken as evaluation measure.

All of the tests were two-sided, and a p-value $<0.05$ was regarded as statistically significant. Calculations were carried out using the $\mathrm{R}$ system for statistical computing (version 2.13.1; R Development Core Team, Vienna, Austria, 2011).

\section{Results \\ $\nabla$}

\section{Patient Characteristics}

A total of 1831 patients were included in this analysis. Their mean age was $58.9( \pm 12.6)$ years, and $24.0 \%(n=429)$ were premenopausal or perimenopausal. The patients' percentage mammographic density was on average $36( \pm 19)$.

\section{Univariate Analysis}

Comparing patients with and without involved lymph nodes showed some differences between these groups, most of which were expected. Patients with positive lymph nodes were more likely to have a high proliferative tumor as assessed by Ki-67, a larger tumor size, were more likely to have a multifocal tumor, a ductal or lobular cancer, an ER and PR negative tumor and a higher grading. No differences were seen with regard to PMD and age (๑ Table 1).

\section{Association of PMD and Nodal Status}

Preliminary logistic regression analysis showed that the continuous predictors of age at diagnosis, Ki-67, tumor size, and PMD fitted best as cubic spline variables, with 2, 2, 3, and 1 degrees of freedom, respectively. Complete patient characteristics are shown in 0 Table 1.

Multiple logistic regression analysis which did not take PMD into account (see "Patients and Methods") identified multifocality, tumor size, histology, Ki-67 and grading as relevant predictive factors for nodal status. The predictors age, PR, and ER did not fulfill the final selection criteria, i.e., their predictive value appeared to be irrelevant, or they were already explained by the other factors. Table 2 shows how often each predictor was selected in the bootstrap-based selection process.

The second bootstrap selection process, which took account of the selected predictors and, in addition, PMD and interactions between PMD and those predictors, added PMD but no interaction term ( Table 2). The improvement of the prediction model 
Table 1 Patient and tumor characteristics and association with nodal status, showing mean and standard deviation (SD) for normally distributed data, median and interquartile range for non-normal continuous or ordinal categorical data and frequency and percentage for categorical data, and p-value of corresponding statistical test (PMD: percentage mammographic density; ER: estrogen receptor; PR: progesterone receptor).

\begin{tabular}{|c|c|c|c|c|c|c|}
\hline \multirow[t]{2}{*}{ Characteristic } & \multirow[t]{2}{*}{ Value } & \multicolumn{2}{|c|}{ Node negative } & \multicolumn{2}{|l|}{ Node positive } & \multirow[t]{2}{*}{ p-value } \\
\hline & & $\begin{array}{l}\text { mean or } \\
\text { median or } \mathrm{N}\end{array}$ & $\begin{array}{l}\text { SD or interquar- } \\
\text { tile range or } \%\end{array}$ & $\begin{array}{l}\text { mean or } \\
\text { median or } \mathrm{N}\end{array}$ & $\begin{array}{l}\text { SD or interquar- } \\
\text { tile range or } \%\end{array}$ & \\
\hline Age at diagnosis & years & 59.1 & 12.3 & 58.5 & 13.0 & 0.37 \\
\hline Ki-67 & \% positive & 15 & $(5,25)$ & 20 & $(10,40)$ & $<0.000001$ \\
\hline Tumor size & $\mathrm{cm}$ & 1.4 & $(1.0,2.0)$ & 2.4 & $(1.5,3.5)$ & $<0.000001$ \\
\hline PMD & $\%$ & 35 & $(20,50)$ & 34 & $(21,47)$ & 0.46 \\
\hline \multirow[t]{2}{*}{ Multifocality } & no & 906 & 80.8 & 437 & 70.6 & $<0.00001$ \\
\hline & yes & 215 & 19.2 & 182 & 29.4 & \\
\hline \multirow[t]{3}{*}{ Tumor type } & ductal & 773 & 65 & 443 & 69.2 & $<0.001$ \\
\hline & lobular & 225 & 18.9 & 138 & 21.6 & \\
\hline & others & 191 & 16.1 & 59 & 9.2 & \\
\hline \multirow[t]{2}{*}{ ER } & negative & 266 & 22.3 & 176 & 27.5 & 0.01 \\
\hline & positive & 925 & 77.7 & 464 & 72.5 & \\
\hline \multirow[t]{2}{*}{ PR } & negative & 390 & 32.7 & 257 & 40.2 & $<0.01$ \\
\hline & positive & 801 & 67.3 & 383 & 59.8 & \\
\hline \multirow[t]{3}{*}{ Grading } & 1 & 189 & 16.1 & 35 & 5.6 & $<0.000001$ \\
\hline & 2 & 769 & 65.6 & 417 & 66.8 & \\
\hline & 3 & 214 & 18.3 & 172 & 27.6 & \\
\hline
\end{tabular}

Table 2 Multiple logistic regression analysis, showing frequencies of selected predictors within the first (excluding percentage mammographic density) and second (including percentage mammographic density) bootstrap-based selection process, and inclusion (yes/no) in the final logistic regression models according to pre-specified criteria. (PMD: percentage mammographic density; ER: estrogen receptor; PR: progesterone receptor).

\begin{tabular}{|c|c|c|c|c|}
\hline \multirow[t]{2}{*}{ Predictor } & \multicolumn{2}{|c|}{ 1st selection procedure } & \multicolumn{2}{|c|}{ 2nd selection procedure } \\
\hline & Frequency (\%) & $\begin{array}{l}\text { Inclusion in final model } \\
\text { without PMD }\end{array}$ & Frequency (\%) & $\begin{array}{l}\text { Inclusion in final model } \\
\text { with PMD }\end{array}$ \\
\hline Multifocality & 100 & yes & $100^{\mathrm{b}}$ & yes \\
\hline Tumor size & 100 & yes & 100 & yes \\
\hline Histology & 92 & yes & 100 & yes \\
\hline Ki-67 & 81 & yes & 100 & yes \\
\hline Grading & 77 & yes & 100 & yes \\
\hline Age at diagnosis & 58 & no & $-c$ & - \\
\hline PR & 35 & no & - & - \\
\hline ER & 25 & no & - & - \\
\hline PMD & -a & - & 91 & yes \\
\hline PMD $\times$ Ki-67 & - & - & 43 & no \\
\hline PMD $\times$ tumor size & - & - & 36 & no \\
\hline PMD $\times$ multifocality & - & - & 30 & no \\
\hline PMD $\times$ grading & - & - & 21 & no \\
\hline PMD $\times$ histology & - & - & 20 & no \\
\hline
\end{tabular}

a PMD and any interaction terms (e. g., PMD x Ki-67) were not considered in the 1st selection process.

b The finally selected predictors in the first selection process ("yes" in column 3) were kept in all bootstrap samples of the second selection process.

c Predictors not included in the final model without PMD ("no" in column 3) were not regarded in the second selection process.

by PMD was not significant ( $\mathrm{p}=0.24$, likelihood ratio test). The OR for PMD per 10 units increase was 0.96 (95\% CI, 0.91 to 1.02 ). The AUC of the final model with PMD was 0.76 , the cross-validated AUC was 0.75. The final model with PMD seemed to be wellcalibrated ( $\mathrm{p}=0.32$, Hosmer-Lemeshow $\mathrm{X}^{2}$ test). $\odot$ Fig. 1 shows that observed frequencies of lymph node involvement and predicted frequencies by the regression model coincided quite well.

\section{Discussion}

We showed in this retrospective study that mammographic density as measured by computer-assisted assessment of percentage mammographic density did not improve the prediction of nodal status. PMD does not seem to be associated with lymphatic spread of breast cancer cells. Other established variables such as multifocality, tumor size, histology, and proliferation already predicted lymph node status with a high degree of accuracy.

Mammographic density correlates to the proportion of radiolucent and radiodense material. While fat tissue is mainly responsible for radiolucency, epithelial cells, fibroblasts, extracellular matrix and other stroma components are responsible for the ab- 


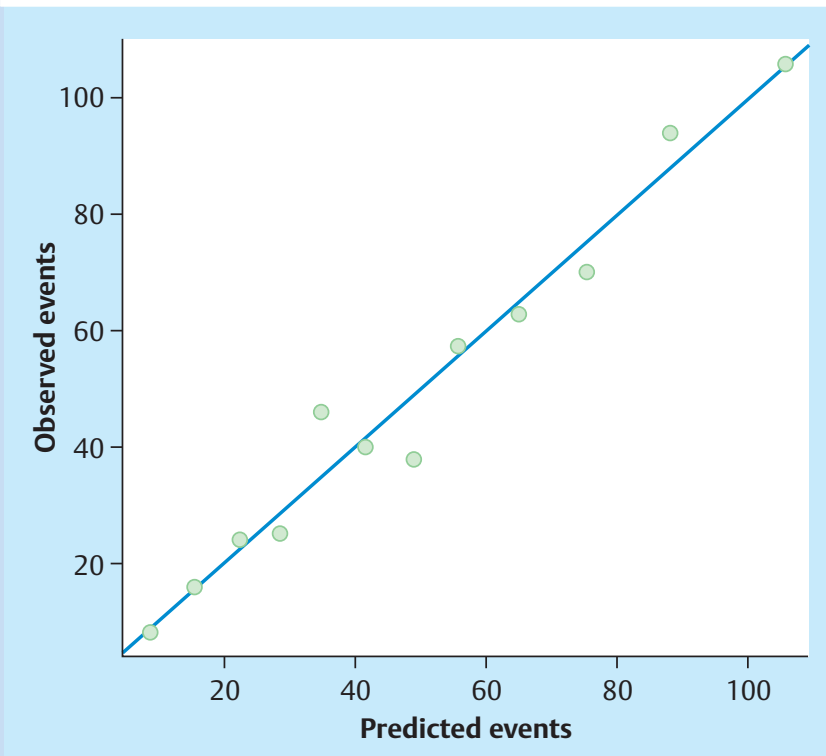

Fig. 1 Observed and predicted frequencies of lymph node status. Patients were ordered according to the predicted probability of a positive lymph node status by the final logistic regression model and grouped into 12 categories based on percentiles. Observed positive lymph node status in each category and summed-up predicted probabilities for a positive lymph node status ("predicted events") in each category are shown. Points below the blue line indicate when the model over-estimates the risk of lymph node positivity, points above the blue line indicate when the model underestimates risk. A perfect prediction model would have all points on the blue line.

sorption of $\mathrm{X}$-ray beams $[17,28,29]$. There is some evidence that lymphangiogenesis is linked to extracellular matrix components such as integrins [30]. Furthermore, several growth factors including fibroblast growth factor (FGF) have been shown to induce lymphangiogenesis [31], which is related to a higher probability for lymph node metastases [30]. Lymph vessels in tumors are not functional due to interstitial tissue hypertension [32], and stroma and extracellular matrix features are similar between tumors and mammographically dense healthy tissue [17]. Therefore the hypothesis seems to be justified that different compositions of the breast extracellular matrix, epithelium and stroma or their correlated MD are associated with an altered lymphangiogenesis pattern and altered probabilities for lymph node metastases when a breast tumor is present in the breast.

In fact, a previous report with a smaller sample size and assessment of mammographic density by ACR BI-RADS categories showed that a lower mammographic density could be associated with a higher probability of axillary lymph node spread [18]. Our study could not confirm these results, neither in the univariate analysis nor in a multivariate analysis taking not only PMD but also all interaction terms into account.

If the focus is not on healthy breast tissue but on the tumor there might be biomarker profiles that link tumor behavior with lymphatic spread and PMD. However, with regard to tumor characteristics there seem to be a few molecular characteristics in addition to tumor size and multifocality such as hormone receptor status and HER2 status that are somewhat associated with lymph node status $[33,34]$. Looking at a genome-wide expression level no expression signature in the tumor that could predict lymph node status could be discovered [35], especially not one that could be linked to mammographic density or other risk factors associated with it.

As there does not seem to be a connection, there might be mechanisms independent of mammographic density including other biological, molecular or immunological factors in the breast which are associated with a positive axillary lymph node status. This study has several strengths and limitations. The BC cases included were hospital based and were not recruited from a population-based screening program. Breast density is thought to contribute to a higher likelihood of tumors being missed during early detection methods for BC. It might therefore be possible for patients with a higher MD to have larger tumors, either caused by detection problems or by a different tumor biology, resulting in a higher likelihood in the group with a higher mammographic density to have larger tumors and a positive lymph node status. In our cohort, the prediction of lymph node status was adjusted for tumor size, which should compensate for a possible imbalance with regard to this issue [38]. One strength of our study is the semiautomated method of quantifying MD with two readers for all images and a mean value for PMD. This could reduce measurement inaccuracies. Another strength is the use of only incident $\mathrm{BC}$ cases, avoiding the risk of bias in the selection of patients due to effects of tumor biology (e.g., hormone receptor status) on survival in patients with BC. Furthermore, the large sample size with more than 1800 patients makes it more likely to discover smaller effects, which our study did not.

\section{Conclusion}

In conclusion, we could not show mammographic density to be associated with the spread of breast cancer tumor cells to the axillary lymph nodes. As mammographic density is mainly a correlate of the amount of extracellular matrix and stroma, the presence or absence of these components and the associated molecular biology do not seem to play a major role in lymphatic spread. Other factors such as tumor size and multifocality already explained the variability of lymph node metastasis to a high degree in our study.

\section{Acknowledgement \\ $\nabla$}

Katharina Heusinger was in part funded by the ELAN program ("Erlangener Leistungsbezogene Anschubfinanzierung und Nachwuchsförderung") of Erlangen University Hospital.

\section{Conflict of Interest}

$\nabla$

The authors declare that they do not have a conflict of interest.

\section{References}

1 Fasching PA, Ekici AB, Adamietz BR et al. Breast cancer risk - genes, environment and clinics. Geburtsh Frauenheilk 2011; 71: 1056-1066

2 Heusinger K, Loehberg CR, Haeberle L et al. Mammographic density as a risk factor for breast cancer in a German case-control study. Eur J Cancer Prev 2011; 20: 1-8

3 Boyd NF, Guo H, Martin LJ et al. Mammographic density and the risk and detection of breast cancer. N Engl J Med 2007; 356: 227-236

4 McCormack VA, dos Santos Silva I. Breast density and parenchymal patterns as markers of breast cancer risk: a meta-analysis. Cancer Epidemiol Biomarkers Prev 2006; 15: 1159-1169

5 Cuzick J, Warwick J, Pinney E et al. Tamoxifen-induced reduction in mammographic density and breast cancer risk reduction: a nested case-control study. J Natl Cancer Inst 2011; 103: 744-752 
6 Boyd NF, Melnichouk O, Martin LJ et al. Mammographic density, response to hormones, and breast cancer risk. J Clin Oncol 2011; 29: 2985-2992

7 Gierach GL, Ichikawa L, Kerlikowske Ket al. Relationship between mammographic density and breast cancer death in the Breast Cancer Surveillance Consortium. J Natl Cancer Inst 2012; 104: 1218-1227

8 Chiu SY, Duffy S, Yen AM et al. Effect of baseline breast density on breast cancer incidence, stage, mortality, and screening parameters: 25 -year follow-up of a Swedish mammographic screening. Cancer Epidemiol Biomarkers Prev 2010; 19: 1219-1228

9 Park CC, Rembert J, Chew K, Moore D, Kerlikowske K. High mammographic breast density is independent predictor of local but not distant recurrence after lumpectomy and radiotherapy for invasive breast cancer. Int J Radiat Oncol Biol Phys 2009; 73: 75-79

10 Verheus M, Maskarinec G, Erber E et al. Mammographic density and epithelial histopathologic markers. BMC Cancer 2009; 9: 182

11 Conroy SM, Pagano I, Kolonel LN, Maskarinec G. Mammographic density and hormone receptor expression in breast cancer: the Multiethnic Cohort Study. Cancer Epidemiol 2011; 35: 448-452

$12 \mathrm{Ma} \mathrm{H}$, Luo J, Press MF et al. Is there a difference in the association between percent mammographic density and subtypes of breast cancer? Luminal A and triple-negative breast cancer. Cancer Epidemiol Biomarkers Prev 2009; 18: 479-485

13 Yaghjyan L, Colditz GA, Collins LC et al. Mammographic breast density and subsequent risk of breast cancer in postmenopausal women according to tumor characteristics. J Natl Cancer Inst 2011; 103: 11791189

14 Heusinger K, Jud SM, Haberle L et al. Association of mammographic density with hormone receptors in invasive breast cancers - results from a case-only study. Int J Cancer 2012; DOI: 10.1002/ijc.27515.

15 Antoni S, Sasco AJ, Dos Santos Silva I, McCormack V. Is mammographic density differentially associated with breast cancer according to receptor status? A meta-analysis. Breast Cancer Res Treat 2013; 137: $337-$ 347

16 Heusinger K, Jud SM, Haberle L et al. Association of mammographic density with the proliferation marker Ki-67 in a cohort of patients with invasive breast cancer. Breast Cancer Res Treat 2012; 135: 885-892

17 DeFilippis RA, Chang H, Dumont $N$ et al. CD36 repression activates a multicellular stromal program shared by high mammographic density and tumor tissues. Cancer Discov 2012; 2: 826-839

18 Wasuthit Y, Kongdan Y, Suvikapakornkul R, Lertsithichai P, Chirappapha $P$. Predictive factors of axillary lymph node metastasis in breast cancer J Med Assoc Thai 2011; 94: 65-70

19 Beckmann MW, Brucker C, Hanf V et al. Quality assured health care in certified breast centers and improvement of the prognosis of breast cancer patients. Onkologie 2011; 34: 362-367

20 Fasching PA, Loehberg CR, Strissel PL et al. Single nucleotide polymorphisms of the aromatase gene (CYP19A1), HER2/neu status, and prognosis in breast cancer patients. Breast Cancer Res Treat 2008; 112: 89-98
21 Fasching PA, Heusinger K, Haeberle L et al. Ki67, chemotherapy response, and prognosis in breast cancer patients receiving neoadjuvant treatment. BMC Cancer 2011; 11: 486

22 Haeberle L, Wagner F, Fasching PA et al. Characterizing mammographic images using generic texture features. Breast Cancer Res 2012; 14: R59

23 Rauh C, Hack CC, Haberle L et al. Percent mammographic density and dense area as risk factors for breast cancer. Geburtsh Frauenheilk 2012; 72: 727-733

24 Ursin G, Astrahan MA, Salane $M$ et al. The detection of changes in mammographic densities. Cancer Epidemiol Biomarkers Prev 1998; 7: $43-$ 47

25 Hastie T, Tibshirani $R$. Generalized additive models for medical research. Stat Methods Med Res 1995; 4: 187-196

26 Sauerbrei $W$, Schumacher $M$. A bootstrap resampling procedure for model building: application to the Cox regression model. Stat Med 1992; 11: 2093-2109

27 Simon R, Altman DG. Statistical aspects of prognostic factor studies in oncology. Br J Cancer 1994; 69: 979-985

28 Li T, Sun L, Miller $N$ et al. The association of measured breast tissue characteristics with mammographic density and other risk factors for breast cancer. Cancer Epidemiol Biomarkers Prev 2005; 14: 343-349

29 Guo YP, Martin LJ, Hanna W et al. Growth factors and stromal matrix proteins associated with mammographic densities. Cancer Epidemiol Biomarkers Prev 2001; 10: 243-248

30 Chen J, Alexander JS, Orr AW. Integrins and their extracellular matrix ligands in lymphangiogenesis and lymph node metastasis. Int J Cell Biol 2012; 2012: DOI: 10.1155/2012/853703

31 Shin JW, Min M, Larrieu-Lahargue F et al. Prox1 promotes lineage-specific expression of fibroblast growth factor (FGF) receptor-3 in lymphatic endothelium: a role for FGF signaling in lymphangiogenesis. Mol Biol Cell 2006; 17: 576-584

32 Less JR, Posner MC, Boucher $Y$ et al. Interstitial hypertension in human breast and colorectal tumors. Cancer Res 1992; 52: 6371-6374

$33 \mathrm{Fehm} T$, Maul H, Gebauer S et al. Prediction of axillary lymph node status of breast cancer patients by tumorbiological factors of the primary tumor. Strahlenther Onkol 2005; 181: 580-586

34 Crabb SJ, Cheang MC, Leung S et al. Basal breast cancer molecular subtype predicts for lower incidence of axillary lymph node metastases in primary breast cancer. Clin Breast Cancer 2008; 8: 249-256

35 Weigelt $B$, Wessels $L F$, Bosma AJ et al. No common denominator for breast cancer lymph node metastasis. Br J Cancer 2005; 93: 924-932

36 Schulz-Wendtland R, Dilbat G, Bani $M$ et al. Full field digital mammography (FFDM) versus CMOS technology versus tomosynthesis (DBT) which system increases the quality of intraoperative imaging? Geburtsh Frauenheilk 2012; 72: 532-538

37 Schulz-Wendtland R, Bani M, Lux MP et al.Pilot study on the detection of simulated lesions using a 2D and 3D digital full-field mammography system with a newly developed high resolution detector based on two shifts of a-Se. Geburtsh Frauenheilk 2012; 72: 408-411

38 Schulz-Wendtland R, Dilbat G, Bani MR et al. Use of tomosynthesis in intraoperative digital specimen radiography - is a reduction of breast reexcision rates possible? Geburtsh Frauenheilk 2011; 71: 1080-1084 